\title{
МЕЖДУНАРОДНЫЙ ОПЫТ ОРГАНИЗАЦИИ РОДСТВЕННОГО УХОДА ЗА ПОЖИЛЫМИ ЛюДЬМИ
}

Статья посвящена исследованию международного опыта государственной поддержки родственного ухода за пожилыми людьми и людьми с инвалидностью. Родственный уход для пожилых людей и людей с инвалидностью зачастую является более желательным и психологически комфортным по сравнению с рыночными и социальными услугами. Учитывая явные издержки, родственный уход выступает наиболее доступным для семьи способом оказать поддержку. Кроме этого, такая забота экономически выгодна для государства в связи с сокращением издержек на социальные услуги для пожилых людей и людей с инвалидностью. В России государственная поддержка родственного ухода только развивается. Одной из основных мер, предусмотренной для лиц, осуществляющих родственный уход, является компенсационная выплата в размере 1200 руб. Исследование ставит своей целью выделить возможные перспективы развития государственной поддержки родственного ухода в России на базе критического анализа международного опыта. Анализ проводился на основе исследований мер социальной поддержки родственного ухода в разных странах мира. Можно выделить три основных уровня поддержки опекунов, обеспечивающих родственный уход: меры финансовой поддержки и услуги, направленные на прямую поддержку опекуна; услуги, косвенно поддерживающие опекуна; институциальная среда, определяющая «правила игры» в реализации родственного ухода. Исследование показало, что финансовая поддержка является наиболее распространённой мерой в Европе. В некоторых других странах (например, Канаде, США) практикуются налоговые льготы для опекуна, обеспечивающего уход за пожилым родственником (человеком с инвалидностью). Однако при этом в статье отмечается, что главным недостатком денежной поддержки является ослабление

Анна Алексеевна Миронова- к.социол.н., научный сотрудник, Институт социальной политики, Национальный исследовательский университет «Высшая школа экономики», Москва, Россия. Электронная почта: amironova@hse.ru 
у опекунов стимулов для участия в формальной занятости. Это делает необходимой реализацию мер, направленных на расширение для опекунов возможностей совмещения трудовой деятельности и родственного ухода. Такие гибкие условия труда для опекунов предусмотрены, например, в Великобритании, Австралии, США и других странах.

Ключевые слова: родственный уход, пожилые люди, инвалиды, социальная поддержка, долгосрочный уход

DOI: 10.17323/727-0634-2021-19-3-465-480

Демографическое старение населения как глобальный процесс затрагивает все страны мира, в том числе и Россию. Согласно прогнозу ООН, доля лиц в возрасте 65 лет и старше в мировом населении в период с 2015 по 2050 гг. увеличится с 8,2\% до 15,9\%, а в населении России- с 13,6\% до 22,9\% (World Population Prospects 2019). При этом процесс демографического старения является исторически новой ситуацией для мирового населения, так как по имеющимся данным, долгое время доля лиц в возрасте старше 60 лет значительно не изменялась и находилась на уровне 5-9\% (Денисенко 2005). В связи с этим актуализируется вопрос о том, как обеспечивать поддержку пожилым людям в стареющем обществе. Помимо материального обеспечения немаловажную роль играют социальные сервисы по уходу за пожилыми людьми, так как с возрастом, как правило, появляются различные функциональные ограничения, связанные с состоянием здоровья.

В России система долговременного ухода за пожилыми возникла с выходом в 1995 г. Федерального закона «О социальном обслуживании граждан пожилого возраста и инвалидов» (Федеральный закон 1995) и в данный момент продолжает формироваться. Так, в феврале 2019 г. утверждён приказ о реализации пилотного проекта по созданию системы долговременного ухода за гражданами пожилого возраста и инвалидами (Приказ Министерства... 2019). Наряду с государственными мерами стали появляться коммерческие и некоммерческие организации, приёмные семьи для пожилых (Парфенова, Петухова 2019). Однако по-прежнему существенная роль в уходе за пожилыми и инвалидами отводится неформальному окружению (родственники, друзья, соседи). В контексте российской культуры межпоколенная родственная забота, как правило, позиционируется как естественная, безальтернативная, вписанная в биографический сценарий (Ткач 2015).

Что касается государственной поддержки родственного ухода, то это направление только развивается. Основной мерой поддержки, предусмотренной для лиц, осуществляющих соответствующий уход, является ежемесячная компенсационная выплата в размере 1200 руб. (Указ Президента РФ 2006). При этом право на получение компенсационной выплаты имеют только граждане в трудоспособном возрасте, «оставившие работу (не поступившие на работу) ввиду необходимости осуществления ухода 
за нетрудоспособными лицами и не имеющие вследствие этого какоголибо дохода в виде заработка либо пенсии (пособия)» (Решение Верховного Суда РФ 2008). Помимо этого, к лицам, осуществляющим уход, применяются и другие требования: постоянное проживание на территории РФ и наличие трудоспособности.

Для дальнейшего эффективного развития долгосрочного ухода за пожилыми людьми и инвалидами в целом и поддержки родственного ухода в частности имеет смысл обратиться к международному опыту в данной сфере. Цель данной статьи- проанализировать международный опыт поддержки лиц, осуществляющих уход за пожилыми и очертить возможные перспективы в развитии государственной поддержки родственного ухода в России. В качестве кейсов для рассмотрения отобраны преимущественно европейские страны, так как именно там система долгосрочного ухода, в том числе поддержка родственного ухода, представлена довольно широко. Также в некоторых случаях анализ дополнен рассмотрением примеров поддержки родственного ухода в США и Канаде.

\section{Место родственного ухода в общей системе обеспечения ухода за пожилыми}

Политика в области организации и финансирования родственного ухода за нетрудоспособными пожилыми людьми в каждой стране имеет свои особенности. Однако в целом ответственность за обеспечение и финансирование долгосрочного ухода разделена между четырьмя основными секторами: семья и неформальный сектор ухода; государственный сектор; сектор волонтерских, негосударственных и некоммерческих организаций; частный сектор (Pijl 1994). Их баланс в каждой стране зависит от множества факторов, таких как традиции, особенности правовой системы, политика в области социальной защиты и здравоохранения, возможности национального бюджета, общее состояние здоровья населения, структура хронических заболеваний в старших возрастах, а также половозрастная структура населения конкретной страны. Например, в странах с более традиционными семейными ценностями и относительно молодым населением основная забота по уходу за пожилыми родственниками, как правило, ложится на плечи семьи. В странах с относительно более старым населением, где демографическая нагрузка пожилыми на трудоспособное население довольно велика, помимо семьи в организацию ухода зачастую включаются государство, волонтёрские организации и частный сектор (Ibid). В условиях развитой социальной политики и активной роли государства в поддержке пожилого населения потребность в обращении к другим источникам поддержки в организации ухода за пожилыми и инвалидами несколько сокращается.

Однако несмотря на различия, например в странах Европы, помощь со стороны семьи играет существенную роль в обеспечении ухода за пожи- 
лыми людьми и инвалидами. К государственной поддержке или рыночным услугам по уходу за пожилыми и инвалидами, как правило, прибегают лишь в том случае, если семья не в состоянии по каким-либо причинам обеспечить такую поддержку (Chiatti et al. 2013: 135). По оценкам исследователей, в Европе до сих пор около $80 \%$ работы по уходу за пожилыми людьми (инвалидами) обеспечивается членами семьи (Ibid).

Можно ли говорить о том, что развитие мер социальной поддержки заменяет собою родственный уход? Обзор исследований о взаимосвязи между формальным и неформальным уходом за пожилыми людьми (инвалидами) показывает противоречивые результаты. В одних исследованиях выявлено, что рост предложения формальной помощи в уходе за пожилыми не влияет на масштаб оказания родственной поддержки по уходу за пожилыми людьми и инвалидами (Christianson 1988; Motel-Klingebiel et al. 2005). Другие исследования (Pezzin et al. 1996; Stabile et al. 2006; Viitanen 2007), напротив, обнаруживают, что в случае роста доступности формального ухода предложение неформального ухода сокращается. Более поздние исследования показывают, что взаимосвязь между формальной и неформальной помощью в уходе за пожилыми (инвалидами) является сложной и зависит от множества обстоятельств. Так, обнаружено, что родственный уход сокращает спрос на низкоквалифицированный уход по найму, в то время как уровень запроса на высококвалифицированный уход, предполагающий наличие профессиональных, в том числе медицинских навыков, сохраняется при наличии родственного ухода (Bonsang 2009). Таким образом, родственный уход может рассматриваться в качестве субститута формального ухода лишь в том случае, когда уход за пожилым (инвалидом) не требует особых навыков. Однако в случае, когда состояние пожилого человека требует профессионального ухода и предполагает значительную нагрузку на ухаживающего, родственная помощь скорее выступает в качестве дополнения к квалифицированному уходу.

Когда речь идёт о родственном уходе за пожилыми и инвалидами в развитых странах, государство не остаётся в стороне, обеспечивая поддержку опекунам, которые реализуют родственный уход. В рамках концепции, предложенной Джулией Твигг и Карлом Аткиным (Twigg, Atkin 1994), выделяется три уровня поддержки опекунов, обеспечивающих родственный уход. К первому уровню относятся меры финансовой поддержки и услуги, направленные на прямую помощь опекунам (например, пособия для опекунов, консультирование, тренинги для опекунов, временный уход за пожилыми и инвалидами в период отдыха лиц, обычно осуществляющих уход за ними). Второй уровень включает услуги, косвенно поддерживающие опекуна (услуги для пожилого человека (инвалида), нуждающегося в уходе). В этом случае непосредственным получателем помощи выступает пожилой человек (инвалид), а выгоды для опекуна сводятся к сокращению нагрузки. Третий уровень поддержки связан 
с формированием институциальной среды, определяющей «правила игры» в реализации родственного ухода (развитость национальной системы организаций по поддержке лиц, нуждающихся в уходе, практики ухода за пожилыми и инвалидами, принятые в данной стране, нормативно-правовое регулирование родственного ухода). На данном уровне не представлены услуги по поддержке опекунов как таковые, однако институциальная среда имеет существенное влияние на то, при каких обстоятельствах будет осуществляться родственный уход. Проанализируем подробнее международный опыт в области реализации мер финансовой поддержки и предоставления услуг, направленных на прямую поддержку опекунов.

\section{Виды финансовой поддержки опекунов: преимущества и недостатки}

В ряде европейских стран предусмотрены различные пособия, обеспечивающие поддержку родственникам, ухаживающим за пожилым человеком. Пособия могут быть адресованы непосредственно лицам, осуществляющим уход за пожилым человеком- прямые пособия (например, Дания, Финляндия, Германия). Также пособия могут выплачиваться самому пожилому человеку (инвалиду), за которым осуществляется уход, чтобы он сам мог передать денежное вознаграждение в пользу того, кто будет за ним ухаживать- косвенные пособия (Австрия, Бельгия, Болгария, Чехия). В отдельных случаях (Англия, Нидерланды, Швеция) данные пособия могут предоставляться и пожилым людям, и тем, кто за ними ухаживает (Courtin et al. 2014).

Пособие, выплачиваемое непосредственно опекуну, призвано, с одной стороны, компенсировать издержки опекуна, связанные с сокращением доходов от трудовой деятельности, а с другой, подчеркнуть социальную значимость его деятельности по родственному уходу. В тех странах, где пособие опекунам предоставляется безотносительно их дохода (например, Финляндия, Швеция), оно преимущественно исполняет роль вознаграждения за труд опекуна. В странах, где пособие опекунам предоставляется на основе оценки их доходной обеспеченности-means-tested (например, Англия, Ирландия), оно позиционируется в первую очередь как некая компенсационная выплата в связи с сокращением трудовых доходов опекуна (Ibid).

Оба варианта выплаты пособия (как самому пожилому человеку (инвалиду), так и непосредственно родственнику, осуществляющему уход) имеют свои недостатки. В случае, когда пособие выплачивается непосредственно человеку, осуществляющему уход, пожилой человек (инвалид) имеет меньше возможностей изменить ситуацию. В то же время когда пособие выплачивается самому пожилому человеку (инвалиду), нуждающемуся в уходе, он имеет больше вариантов в выборе опекуна и определении условий, на которых будет организован уход за ним. С другой стороны, эта ситуация может 
оказаться несправедливой по отношению к опекуну, так как пожилой человек (инвалид) может распорядиться пособием не в пользу того родственника (опекуна), который действительно берёт на себя основную нагрузку по уходу (Kohler et al. 2006). Кроме того, выплата, адресованная получателю услуг по уходу, избавляет разработчиков социальной политики от трудностей, связанных с идентификацией основного опекуна, осуществляющего уход в случае, если, например, опекунов несколько. Не все из тех, кто задействован в родственном уходе, сами признают себя опекунами, что затрудняет прямое предоставление им выплат (Courtin et al. 2014).

Согласно имеющимся данным, финансовая помощь является наиболее распространённым способом поддержки опекунов в Eвропе (Courtin et al. 2014). При этом косвенные выплаты опекунам (в случае, когда выплату получают те, за кем ухаживают, и затем передают её в пользу опекуна) значительно чаще распространены, чем прямые выплаты (в случае, когда получателем выплаты является сам опекун). Среди 23 (из 27) стран Европейского союза, где опекунам, осуществляющим родственный уход, предоставляется финансовая поддержка, прямые выплаты опекунам предусмотрены только в девяти странах. При этом предоставление выплат в поддержку опекунов и их размер, как правило, зависят от различных условий, по-разному определяемых в каждой отдельной стране. Среди таких условий: уровень дохода потенциального получателя выплаты, степень ограничений по состоянию здоровья реципиента ухода, продолжительность предоставляемых услуг по уходу, наличие занятости у опекуна и др. (Ibid).

В некоторых странах государство ограничивает время родственного ухода за пожилым (инвалидом). Например, в Люксембурге использование неформального оплачиваемого ухода ограничено 10,5 часами в неделю (Courtin et al. 2014). Если пожилому человеку (инвалиду) требуется больше часов в неделю, то услуги родственного ухода охватывают не более положенной нормы, а ответственность за него в остальное время ложится на специализированные службы. В случае если уход требуется в течение более чем 14 часов в неделю, то ответственность за его предоставление полностью ложится на специализированные службы (Kohler et al. 2006).

Достаточно распространённым критерием предоставления выплаты опекунам, осуществляющим родственный уход, является доходная обеспеченность (Colombo et al. 2011). С одной стороны, предоставление выплат на основе оценки нуждаемости имеет ряд плюсов: в этом случае у опекуна остаётся больше стимулов к тому, чтобы совмещать трудовую деятельность и родственный уход; предоставление выплаты на основе оценки нуждаемости обеспечивает экономию государственных средств. С другой стороны, предоставление выплаты с учётом доходной обеспеченности влечёт за собой трудности, связанные с разработкой критериев доходной нуждаемости и контролем за соответствие этим критериям. 
Общий размер государственных расходов на организацию домашнего ухода за пожилыми и инвалидами (в том числе на поддержку родственного ухода) в странах ОЭСР составляет более $30 \%$ от государственных расходов на долгосрочный уход и варьирует от 0,2\% от ВВП в Испании до 2,75\% в Швеции (Tarricone, Tsouros 2008: 18-19). Хотя сведения о размерах выплат опекунам ограничены, по имеющимся оценкам, несмотря на существенные различия между европейскими странами, размер выплаты, направленной на поддержку опекуна, осуществляющего родственный уход, как правило, относительно невысокий. Так, в большинстве стран ОЭСР размер денежных выплат, выделяемых на поддержку родственного ухода, как правило, не превышает $30 \%$ от средней заработной платы (OECD 2005).

Зачастую эксперты критично относятся к денежным выплатам от государства как способу поддержки опекуна, реализующего родственный уход (Colombo et al. 2011). Одним из основных последствий данного вида поддержки выступает то, что получая подобного роды выплаты, опекуны рискуют попасть в «ловушку» низкодоходности или уйти в теневой сектор экономики, имея мало стимулов для участия в формальной занятости. В связи с этим необходимо реализовывать меры, направленные на расширение возможностей опекунов для совмещения трудовой деятельности и родственного ухода. Гибкие условия труда для опекунов, осуществляющих родственный уход, предусмотрены, например, в Великобритании, Австралии и США. Кроме этого, в отдельных странах (например, Канада, США) практикуются налоговые льготы для опекуна, обеспечивающего уход за пожилым родственником или инвалидом (Ibid).

\section{Услуги и льготы для опекуна, осуществляњего уход: проблемы и решения}

Люди, которые оказывают полноценный ежедневный уход за пожилым родственником (инвалидом), подвержены повышенной психологической нагрузке и стрессу. Особенно это касается тех, кто ухаживает за людьми с психическими особенностями и расстройствами. Те, кто обеспечивают родственный уход за пожилыми и инвалидами, в три раза чаще признают себя нездоровыми по сравнению с теми, кто не участвует в организации такого рода поддержки (Colombo et al. 2011). В целом к негативным последствиям, возникающим у донора помощи (опекуна) в связи с длительным уходом, можно отнести: нарастание психологических проблем; сокращение доходов в связи с переходом на частичную занятость или полным уходом с рынка труда; сокращение свободного времени на отдых и заботу о других членах семьи, социальную изоляцию (Thinnes, Padilla 2011; Boots et al. 2014).

Как показывают исследования, в роли тех, кто обеспечивает родственный уход за пожилыми людьми и инвалидами, выступают в основном 
люди в возрасте около 55 лет, большая часть из которых - женщины (Chiatti et al. 2013: 136). Среди тех, кто ухаживает за пожилыми родственниками, как правило, больше неработающих. При этом значительная доля занятых сообщают, что им приходится сокращать рабочее время в связи с необходимостью обеспечивать уход за пожилым родственником или инвалидом (Ibid).

Для того чтобы ограничить снижение качества жизни опекуна, обусловленное родственным уходом, в развитых странах реализуется ряд услуг по поддержке опекунов: услуги кратковременного замещения опекуна, осуществляющего родственный уход (отпуск для опекуна), информирование, консультирование, проведение специализированных тренингов. Услуга кратковременного замещения опекуна предполагает временное предоставление ухода за зависимым пожилым человеком (инвалидом) дома или в специализированном учреждении людьми, не являющимися основными опекунами. Информирование предполагает информационную поддержку опекунов, например, по вопросам обеспечения ухода или о доступных услугах для опекунов и лиц, нуждающихся в уходе. Консультирование заключается, например, в оказании психологической поддержки опекунам для преодоления стрессовых ситуаций. Тренинги позволяют опекунам приобретать навыки и перенимать опыт по организации ухода за пожилыми (инвалидами).

Наиболее распространённым видом услуг для опекуна, осуществляющего уход за пожилым человеком или инвалидом, является предоставление ему времени, свободного от выполнения обязательств по уходу (отпуск опекуна). В некоторых странах (например, в Бельгии и Нидерландах) функции по уходу за пожилым или инвалидом на время отдыха опекуна частично берут на себя волонтёрские организации (Kohler et al. 2006).

Другим направлением поддержки опекунов является организация практических тренингов, где опекуны могут получить навыки ухода за пожилыми и инвалидами, а также навыки психологической адаптации к стрессовым ситуациям в условиях необходимости оказывать длительный уход (Ирландия, Финляндия, Нидерланды, Франция, Бельгия). Практикуются ситуации, когда такого рода тренинги организуются под руководством людей, имеющих собственный опыт родственного ухода за пожилыми и инвалидами (Kohler et al. 2006; Mestheneos, Triantafillou 2005).

Помимо непосредственных услуг, направленных на поддержку опекуна, занятого родственным уходом, в международной практике также существует опыт реализации мер, направленных на расширение возможностей опекуна совмещать родственный уход с трудовой деятельностью. Предоставление опекуну, занятому родственным уходом, возможности продолжать трудовую деятельность на гибких условиях признаётся большинством стран-членов ОЭСР одним из важнейших направлений государственной поддержки родственного ухода (Colombo et al. 2011). Как 
показывают исследования, отпуск по семейным обстоятельствам и возможность работать на гибких условиях повышают вероятность сохранения занятости у женщин, занятых родственным уходом. В то же время общий эффект данной меры неоднозначен-установление льготных условий труда для опекунов может снизить шансы устроиться на работу у опекунов, находящихся в поисках работы (Pavalko, Henderson 2006).

В большей части стран ОЭСР, по которым доступны данные, длительность оплачиваемого отпуска для опекуна, обеспечивающего родственный уход, составляет меньше месяца или определяется продолжительностью терминального состояния умирающего родственника. Наиболее длительный оплачиваемый отпуск (максимум при наиболее сложных обстоятельствах ухода- 12 месяцев) по уходу за пожилым родственником (инвалидом), предоставляется в Бельгии (Courtin et al. 2014: 14). В Японии опекун, осуществляющий родственный уход, может претендовать на 93 дня отпуска по уходу за пожилым родственником (инвалидом) с сохранением 40 \% заработной платы. В случае если работодатель отказывается оплачивать время пребывания в отпуске, то сохранение заработной платы обеспечивается посредством фонда страхования занятости (еmployment insurance). Наиболее высокий уровень замещения заработной платы в период отпуска опекуна зафиксирован в Норвегии и Швеции. Здесь размер компенсации на период отпуска составляет соответственно $100 \%$ и $80 \%$ от заработной платы (Colombo et al. 2011).

Что касается возможной длительности неоплачиваемого отпуска для опекуна, занятого родственным уходом, то она, как правило, значительно выше, чем продолжительность оплачиваемого отпуска. В ряде стран (например, Бельгия, Франция, Испания, Ирландия) продолжительность неоплачиваемого отпуска для опекуна в отдельных случаях может составлять от одного года и больше. При этом предоставление такого отпуска может предполагать соблюдение некоторых условий. Например, во Франции получить длительный отпуск могут только те опекуны, кто ухаживает за родственником, имеющим не менее 80 \% утраты автономности. В некоторых странах (например, Ирландия и Испания) неоплачиваемый отпуск в связи с необходимостью оказания родственного ухода не имеет законодательной основы, поэтому работодатели вправе отказать в предоставлении такого отпуска (Colombo et al. 2011). Однако имеются сведения о том, что даже в тех странах, где опекуны пожилых родственников (инвалидов) официально имеют право на дополнительный отпуск, на практике это право бывает труднореализуемо, поскольку частные компании отказываются предоставлять дополнительный отпуск данной категории граждан (Kohler et al. 2006).

Несмотря на позитивные эффекты, которые предполагает данная мера поддержки, есть и некоторые возможные нежелательные последствия. В отличие от отпуска по уходу за ребёнком, которым пользуются в начале или в середине своей трудовой карьеры, отпуск по уходу за пожилым 
родственником (инвалидом), как правило, приходится на более поздний этап жизненного цикла (как было отмечено выше, опекуны, осуществляющие родственный уход, чаще всего относятся к возрасту старше 45-50 лет). В связи с этим отпуск, предоставляемый опекунам, может использоваться как своего рода ранний выход на пенсию, особенно в случае, если этот отпуск хорошо оплачивается (Colombo et al. 2011).

\section{Заключение}

Анализ международного опыта в организации ухода за пожилыми людьми и инвалидами выявил существенные различия в отношении того, кем и как обеспечивается уход. Однако несмотря на значительный разброс в сфрере оказания помощи зависимым пожилым людям и инвалидам, практически во всех странах основная часть помощи в обеспечении ухода реализуется членами семьи. Даже в такой стране, как Швеция, где государство традиционно выступает одним из ключевых акторов поддержки населения, стремление пожилых людей (инвалидов) как можно дольше оставаться в своём доме привело к «открытию семейного ухода заново» (Johansson 2004: 15). Данная тенденция, появившаяся в условиях экономического спада, проявилась в растущем общественном признании, что государственная поддержка родственного ухода является одним из самых оптимальных решений в обеспечении нужд пожилых людей. В результате в конце 1990-х гг. в Швеции принят трёхлетний план действий, обязывающий местные власти обеспечивать меры поддержки лицам, реализующим родственный уход. Вскоре был выделен национальный грант в размере около 33 млн евро в рамках проекта «Опекун 300» для стимулирования развития мер поддержки опекунов, осуществляющих родственный уход. Реализация данных мер привлекла внимание к значимости родственного ухода и поставила на повестку дня вопрос о государственных мерах поддержки родственного ухода (Ibid).

В пользу важнейшего значения родственного ухода за пожилыми и инвалидами выделим ряд его преимуществ по сравнению с рыночными или социальными услугами. Во-первых, родственный уход зачастую является наиболее желательным и психологически комфортным для самих пожилых людей или инвалидов, нуждающихся в уходе. Во-вторых, с точки зрения явных издержек родственный уход является самым доступным для семьи. В-третьих, родственный уход создаёт значительную экономию для государства на предоставлении социальных услуг для пожилых людей и инвалидов. Например, по оценкам швейцарских экспертов, экономический вес родственного ухода был оценен в 10-12 биллионов швейцарских франков, что превысило суммарные расходы на социальные услуги по уходу на дому и в специализированных учреждениях (Kohler et al. 2006: 16).

Наряду с достоинствами можно выделить и ряд недостатков родственного ухода за пожилыми и инвалидами, которые, безусловно, нужно принимать 
во внимание при реализации мер социальной поддержки. Во-первых, родственный уход, как правило, не предполагает наличия у опекуна профессиональных навыков, что может негативно отразиться на качестве ухода. Вовторых, родственный уход может сопровождаться обострением конфликтных ситуаций в семье и насилием над пожилыми людьми (инвалидами), что негативно сказывается на психологическом здоровье как пожилых (инвалидов), так и опекунов. В-третьих, обеспечение родственного ухода имеет ряд негативных последствий для опекуна в виде ослабления его психологического и физического здоровья, социальной изоляции, сокращения доходов. В-четвёртых, участие в родственном уходе отрицательно сказывается на предложении рабочей силы на рынке труда, так как опекуны, как правило, вынуждены значительно ограничивать своё участие на рынке труда или вовсе отказываться от трудовой деятельности.

Политическая дискуссия относительно роли семейного ухода в обеспечении нужд пожилых людей и инвалидов в ряде стран отсутствует (Kohler et al. 2006). В некоторых странах это обусловлено тем, что родственный уход воспринимается как должное, как занятие, не требующее вмешательства государства (например, Болгария, Мальта, Польша, Греция, Словения, сюда также можно отнести и Россию). В других странах (например, в Дании) напротив- эта дискуссия отсутствует, потому что государство берёт на себя значительную долю ответственности по обеспечению нужд пожилых людей и инвалидов в рамках ухода. В других странах проблема нарастающей потребности в уходе за пожилыми и инвалидами в связи со старением населения включена в повестку дня (например, Бельгия, Чехия, Италия, Франция, Швейцария). Однако несмотря на различную степень осознанности в разных странах относительно роли родственного участия в обеспечении ухода за нетрудоспособными людьми старших возрастов, остаётся очевидной необходимость каким-то образом решать проблему обеспечения нарастающего спроса на уход со стороны пожилого населения.

В России семья продолжает играть ключевую роль в обеспечении ухода за пожилыми и инвалидами. Однако демографические тенденции, среди которых снижение рождаемости и рост доли пожилых родственников в структуре семейной группы, снижают возможности осуществления родственного ухода за счёт сокращения числа представителей молодого поколения в семье. Таким образом, в условиях роста доли пожилых людей нагрузка на молодых членов семьи, предоставляющих родственный уход, будет увеличиваться. В связи с этим всё более актуализируется необходимость государственной поддержки родственного ухода, поэтому международный опыт в этом отношении может оказаться очень полезным.

\section{Выражения признательности}

Исследование осуществлено в рамках Программы фундаментальных исследований НИУ ВШЭ в 2019 г. 


\section{Список источников}

Денисенко М. (2005) Тихая революция. Отечественные записки, 3 (24): 16-30.

Парфенова О.А., Петухова И.С. (2019) Конкуренция за заботу о пожилых: тактики социальных сервисов в новых условиях. Мониторинг общественного мнения: Экономические и социальные перемены, (4): 173-186.

Приказ Министерства труда и социальной защиты РФ (2019) О реализации пилотного проекта по созданию системы долговременного ухода за гражданами пожилого возраста и инвалидами в пилотных регионах в 2019 году № 128 от 28.02.2019.

Решение Верховного Суда РФ (2008) Об отказе в удовлетворении заявления о признании недействующими подпунктов «в» пунктов 6 и 9 Правил осуществления ежемесячных компенсационных выплат неработающим трудоспособным лицам, осуществляющим уход за нетрудоспособными гражданами, утв. Постановлением Правительства РФ от 04.06.2007 N 343 N ГКПИ07-1416 от 04.02.2008.

Ткач О. А. (2015) «Заботливый дом»: уход за пожилыми родственниками и проблемы совместного проживания. Социологические исследования, (10): 94-102.

Указ Президента РФ (2006) О компенсационных выплатах лицам, осуществляющим уход за нетрудоспособными гражданами № 1455 от 26.12.2006.

Федеральный закон (1995) О соииальном обслуживании граждан пожилого возраста и инвалидов № 122-ФЗ от 02.08.1995.

Bonsang E. (2009) Does Informal Care from Children to Their Elderly Parents Substitute for Formal Care in Europe? Journal of Health Economics, 28 (1): 143-154.

Boots L.M.M., de Vugt M.E., Van Knippenberg R. J.M., Kempen G.I.J.M., Verhey F.R.J. (2014) A Systematic Review of Internet-based Supportive Interventions for Caregivers of Patients with Dementia. International Journal of Geriatric Psychiatry, 29 (4):331-344.

Chiatti C., Melchiorre M.G., Di Rosa M., Principi A., Santini S., Döhner H., Lamura G. (2013) Family Networks and Supports in Older Age. In: C. Phellas (ed.) Aging in European Societies. Boston, MA: Springer: 133-150.

Christianson J. B. (1988) The Evaluation of the National Long-term Care Demonstration: The Effect of Channelling on Informal Caregiving. Health Services Research, 23 (1):99-117.

Colombo F., Francesca C., Ana L.N., Jérôme M., Frits T. (2011) Help Wanted?: Providing and Paying for Long-Term Care. Paris: OECD Publishing.

Courtin E., Jemiai N., Mossialos E. (2014) Mapping Support Policies for Informal Carers Across the European Union. Health Policy, 118 (1): 84-94.

Johansson L. (2004) National Background Report for Sweden. Available at: https:/clck. ru/NrSUK (accessed 15 January 2020).

Kohler S., Schreiber D., Döhner H. (2006) Services for Supporting Family Carers of Elderly People in Europe: Characteristics, Coverage and Usage. Available at: https://clck. $\mathrm{ru} / \mathrm{NrSfC}$ (accessed 28 January 2020).

Mestheneos E., Triantafillou J. (2005) Supporting Family Carers of Older People in Europe-The Pan-European Background Report. Münster: Lit Verlag. 
Motel-Klingebiel A., Tesch-Roemer C., Von Kondratowitz H. J. (2005) Welfare States do not Crowd Out the Family: Evidence for Mixed Responsibility from Comparative Analyses. Ageing and Society, 25 (6): 863-882.

OECD (2005) Long-term Care for Older People. Paris: OECD.

Pavalko E. K., Henderson K. A. (2006) Combining Care Work and Paid Work: Do Workplace Policies Make a Difference? Research on Aging, 28 (3):359-374.

Pezzin L.E., Kemper P., Reschovsky J. (1996) Does Publicly Provided Home Care Substitute for Family Care? Experimental Evidence with Endogenous Living Arrangements. The Journal of Human Resources, 31 (3): 650-676.

Pijl M. (1994) When Private care Goes Public. In: A. Evers, M. Pijl, C. Ungerson (eds.) Payments for care: a comparative overview. Aldershot: Avebury:3-18.

Stabile M., Laporte A., Coyte P.C. (2006) Household Responses to Public Home Care Programs. Journal of Health Economics, (25): 674-701.

Tarricone R., Tsouros A. D. (eds.) (2008) Home Care in Europe: The Solid Facts. Copenhagen: WHO Regional Office Europe.

Thinnes A., Padilla R. (2011) Effect of Educational and Supportive Strategies on the Ability of Caregivers of People with Dementia to Maintain Participation in That Role. American Journal of Occupational Therapy, 65 (5): 541-549.

Twigg J., Atkin K. (1994) Carers Perceived: Policy and Practice in Informal Care. Buckingham: Open University Press.

Viitanen T.K. (2007) Informal and Formal Care in Europe. IZA Discussion Paper, № 2648.

World Population Prospects (2019) Demographic Profiles, Volume II. Available at: https://clck.ru/NNr75 (accessed 23 October 2019). 
Anna Mironova

\section{INTERNATIONAL EXPERIENCE IN THE ORGANIZATION OF INFORMAL CARE FOR THE ELDERLY}

This article examines international experience in the state provision of family care for the elderly. Family care is often more desirable and psychologically comfortable for elderly and disabled people than market-based and social services. In terms of explicit costs, family care is usually the most affordable way for the family to provide support. Moreover, family care is cost-effective for the state due to cost reduction in social services for elderly and disabled people. In Russia, a system of state support for family care is still developing. One of the main state measures for supporting caregivers is a compensation payment of 1200 rubles. The study aims to outline possible prospects for the development of state support for family care in Russia based on a critical analysis of international experience. The analysis was based on existing research on social support measures for family care in different countries. In general, there are three main governmental levels of supporting measures for family caregivers: financial support and services directly intended to the caregiver; services indirectly supporting caregivers; and the institutional environment that determines the 'rules of the game' in implementing kinship care. The author found that financial support is the most common way to support caregivers in Europe. In some other countries (for example, Canada, USA) there are tax benefits for those providing care. However, it was mentioned that the main disadvantage of monetary support for caregivers is that this reduces opportunities for formal employment. In that regard, it is necessary to implement measures to support the ability of caregivers to combine work and family care. Flexible working conditions for caregivers are provided, for example, in the UK, Australia, USA and other countries.

Key words: family care, elderly, disabled people, social support, long-term care

DOI: 10.17323/727-0634-2021-19-3-465-480

\section{References}

Bonsang E. (2009) Does Informal Care from Children to Their Elderly Parents Substitute for Formal Care in Europe? Journal of Health Economics, 28 (1): 143-154.

Boots L. M.M., de Vugt M.E., Van Knippenberg R. J.M., Kempen G. I.J.M., Verhey F. R.J. (2014) A Systematic Review of Internet-based Supportive Interventions for Caregivers of Patients with Dementia. International Journal of Geriatric Psychiatry, 29 (4):331-344.

Anna A. Mironova- Cand. Sci (Sociol.), research fellow, Institute of Social Policy, National Research University 'Higher school of Economics', Moscow, Russian Federation. Email: amironova@hse.ru 
Chiatti C., Melchiorre M. G., Di Rosa M., Principi A., Santini S., Döhner H., Lamura G. (2013) Family Networks and Supports in Older Age. In: Phellas C. (ed.) Aging in European Societies. Boston, MA: Springer: 133-150.

Christianson J. B. (1988) The Evaluation of the National Long-term Care Demonstration: The Effect of Channeling on Informal Caregiving. Health Services Research 23 (1):99-117.

Colombo F., Francesca C., Ana L. N., Jérôme M., Frits T. (2011) Help Wanted? Providing and Paying for Long-Term Care. Paris: OECD Publishing.

Courtin E., Jemiai N., Mossialos E. (2014) Mapping Support Policies for Informal Carers Across the European Union. Health Policy, 118 (1): 84-94.

Decree of the President of the Russian Federation (2006) O kompensacionnyh vyplatah licam, osushhestvljajushhim uhod za netrudosposobnymi grazhdanami [Compensation Payments to Persons Caring for Disabled Citizens] N 1455 from 26.12.2006.

Denisenko M. (2005) Tihaja revoljucija [Quiet Revolution]. Otechestvennye zapiski [Homeland Notes], 3 (24): 16-30.

Federal Law (1995) O sotsial'nom obsluzhivanii grazhdan pozhilogo vozrasta i invalidov [About Social Services for Elderly and Disabled People] N 122-FZ from 2.08.1995.

Johansson L. (2004) National Background Report for Sweden. Available at: https://clck. $\mathrm{ru} / \mathrm{NrSUK}$ (accessed 15 January 2020).

Kohler S., Schreiber D., Döhner H. (2006) Services for Supporting Family Carers of Elderly People in Europe: Characteristics, Coverage and Usage. Available at: https://clck. $\mathrm{ru} / \mathrm{NrSfC}$ (accessed 28 January 2020).

Mestheneos E., Triantafillou J. (2005). Supporting Family Carers of Older People in Europe-The Pan-European Background Report. Münster: Lit Verlag.

Motel-Klingebiel A., Tesch-Roemer C., Von Kondratowitz H. J. (2005) Welfare States do not Crowd Out the Family: Evidence for Mixed Responsibility from Comparative Analyses. Ageing and Society, 25 (6): 863-882.

OECD (2005) Long-term Care for Older People. Paris: OECD.

Order of the Ministry of Labor and Social Protection in the Russian Federation (2019) O realizacii pilotnogo proekta po sozdaniju sistemy dolgovremennogo uhoda za grazhdanami pozhilogo vozrasta i invalidami v pilotnyh regionah $v 2019$ godu [Implementation of the Pilot Project to Create a System of Long-Term Care for Elderly and Disabled People in Pilot Regions in 2019] N 128 from 28.02.2019.

Parfenova O. A., Petuhova I. S. (2019) Konkurencija za zabotu o pozhilyh: taktiki social'nyh servisov v novyh uslovijah [Competition for the Care of the Elderly: Strategies of Social Services in a New Environment]. Monitoring obshhestvennogo mnenija: Jekonomicheskie i social'nye peremeny [Monitoring of Public Opinion: Economic and Social Changes], (4): 173-186.

Pavalko E. K., Henderson K. A. (2006) Combining Care Work and Paid Work: Do Workplace Policies Make a Difference? Research on Aging, 28 (3): 359-374. 
Pezzin L. E., Kemper P., Reschovsky J. (1996) Does Publicly Provided Home Care Substitute for Family Care? Experimental Evidence with Endogenous Living Arrangements. The Journal of Human Resources, 31 (3): 650-676.

Pijl M. (1994) When Private Care Goes Public. In: A. Evers, M. Pijl, C. Ungerson (eds.) Payments for Care: A Comparative Overview. Aldershot: Avebury: 3-18.

Supreme Court of the Russian Federation (2008) Ob otkaze v udovletvorenii zajavlenija o priznanii nedejstvujushhimi podpunktov ' $V$ ' punktov 6 i 9 Pravil osushhestvlenija ezhemesjachnyh kompensacionnyh vyplat nerabotajush him trudosposobnym licam, osushhestvljajushim uhod za netrudosposobnymi grazhdanami, utv. Postanovleniem Pravitel'stva RF ot 04.06.2007 N 343 [On Rejection of Claims about the Recognition of the Voiding of the Paragraph ' $V$ ' and Points 6 and 9 of the Guidelines of Monthly Payments to Unemployed Persons who Take Care for Disabled Citizens Enacted by the Order of the Government of the RF on 4.6.2007 N 343] N GKPI07-1416 from 04.02.2008.

Stabile M., Laporte A., Coyte P. C. (2006) Household Responses to Public Home Care Programs. Journal of Health Economics, (25): 674-701.

Tarricone R., Tsouros A. D. (eds.) (2008) Home Care in Europe: The Solid Facts. Copenhagen: WHO Regional Office Europe.

Thinnes A., Padilla R. (2011) Effect of Educational and Supportive Strategies on the Ability of Caregivers of People with Dementia to Maintain Participation in that Role. American Journal of Occupational Therapy, 65 (5): 541-549.

Tkach O.A. (2015) 'Zabotlivyj dom': uhod za pozhilymi rodstvennikami i problemy sovmestnogo prozhivanija ['Caring Home': Care for Elderly Relatives and Problems of Cohabitation]. Sociologicheskie issledovanija [Sociological Research], (10):94-102.

Twigg J., Atkin K. (1994) Carers Perceived: Policy and Practice in Informal Care. Buckingham: Open University Press.

Viitanen T.K. (2007) Informal and Formal Care in Europe. IZA Discussion Paper, No 2648.

World Population Prospects (2019) Demographic Profiles, Volume II. Available at: https:// clck.ru/NNr75 (accessed 23 October 2019). 